\title{
Why Use Anything But a Standard Spontaneous Breathing Trial to Determine Readiness for Ventilator Discontinuation?
}

In recent years, there has been an increased emphasis on the need for daily spontaneous breathing trial (SBT) assessment and performance of SBTs where indicated. ${ }^{1}$ The implementation of the ABCDE bundle (awakening, spontaneous breathing trial, coordinated efforts between health professionals, standardized delirium assessment, early mobilization) to improve liberation from the ventilator has prompted us to refocus our attention on the importance of daily assessment of the need for sedation and the early initiation of SBTs in every mechanically ventilated patient. Based on current recommendations, the ideal approach to perform an SBT is to allow spontaneous unsupported breathing for $30 \mathrm{~min}$ to $2 \mathrm{~h}^{2,3}$ This can be accomplished via the mechanical ventilator (zero PEEP and zero pressure support) or via a standard T-piece.

Brochard et $\mathrm{al}^{4}$ demonstrated that in a selected population of patients, those having first failed an SBT, weaning was faster with pressure support ventilation (PSV), although subsequent trials have shown that the performance of an SBT, with or without PSV, results in the same outcome. ${ }^{5}$ In this issue of RESPIRATORY CARE, Teixeira et $\mathrm{al}^{6}$ conducted a randomized comparison of approaches to an SBT. They compared the efficacy of PSV to a T-tube and to the use of proportional assist ventilation (PAV) during the SBT in a heterogeneous population of 160 critically ill subjects with respiratory failure from several etiologies requiring ventilatory support for $>24 \mathrm{~h}$. Although their protocol was sound, their results showed no clinically relevant differences between groups. They found that length of mechanical ventilation, length of hospitalization, extuba-

\footnotetext{
Dr Kacmarek has disclosed relationships with Venner Medical, Covidien, and Orange Med. Dr Villar has disclosed relationships with Maquet, Instituto de Salud Carlos III, Fundación Mutua Madrileña, and Asociación Científica Pulmón y Ventilación Mecánica. Dr Blanch is inventor of one Corporació Sanitaria Parc Taulí-owned United States patent: "Method and system for managed related patient parameters provided by a monitoring device" (United States Patent 12/538,940). Dr Blanch is founder of BetterCare, which is a research and development spinoff of Corporació Sanitària Parc Taulí (Spain).
}

Correspondence: Robert M Kacmarek RRT PhD FAARC, Department of Respiratory Care, Massachusetts General Hospital, 55 Fruit Street, Boston, Massachusetts 01460. E-mail: rkacmarek@partners.org.

DOI: $10.4187 /$ respcare.04535 tion failure, time to re-intubation, and need for tracheostomy were similar among groups. Essentially, it did not matter which approach was used to assess for extubation readiness.

The results of this study are exactly what we expected! As indicated above, when all patient types are compared, the use of PSV during an SBT results in the same outcome as a T-piece. ${ }^{7}$ In addition, the authors indicate that there have been 3 previous comparisons of PAV with PSV during SBTs, all with negative results. ${ }^{8-10}$ Most importantly, the patient population they chose to study was one that generally can be rapidly discontinued from ventilatory support once weaning criteria are met. About $50 \%$ of the subjects randomized were trauma victims, $\sim 20 \%$ were subjects from the medical ICU, $\sim 23 \%$ had a history of COPD, and only $\sim 20 \%$ had a body mass index of $>30 \%$. The overall ICU mortality of the group was $3.7 \%$, and hospital mortality was $10 \%$. The bottom line is that the study population was one in which no one would expect any intervention affecting the way an SBT was conducted to have an effect on the process of ventilator discontinuation or on mortality.

See the Original Study on Page 1527

We believe that the most important factor that affected a lack of difference in the time to extubation, which was $6.6 \pm 4.2 \mathrm{~d}$, was the fact that before the SBT, these subjects were ventilated with the volume control continuous mandatory ventilation (VC-CMV) mode. Recent data would indicate that asynchrony is greater in VC-CMV than in PSV, ${ }^{11}$ probably because of the 4 potential variables controlled by the ventilator during inspiration (pressure, flow, volume, and time), 3 are controlled during ventilation VC-CMV. This means that the patient must accept on every breath a set non-varying delivered tidal volume, the set inspiratory time, and a set peak flow and flow waveform: not an easy task! As a result, asynchrony, primarily in the form of double triggering ${ }^{11,12}$ and flow asynchrony, ${ }^{13,14}$ is common during VC-CMV and recent data indicate that there is an association between asynchrony and length of mechanical ventilation, ${ }^{11}$ length of ICU stay, ${ }^{12}$ and mortality. ${ }^{15}$ In PSV, the only variable controlled by the ventilator is the set pressure; the patient on a breath-to-breath basis can vary tidal volume, inspiratory time, and peak flow: a much easier task. 
With PAV, a different approach to ventilatory support is provided. ${ }^{16}$ Instead of the ventilator forcing the patient to accept the ventilatory pattern set by the clinician, with PAV, the ventilator follows the patient. In PAV, we do not set pressure, flow, volume, or time. The only variable that is set is the percentage of the inspiratory effort that is provided by the ventilator. The ventilator allows the user to adjust the proportion of effort to maintain patient work mostly in the normal spontaneous work of breathing range $(0.3-0.7 \mathrm{~J} / \mathrm{L})$. As patient effort increases, the ventilator pressure work also increases. This is exactly the opposite of VC-CMV, where more work performed by the patient means less work performed by the ventilator. In pressure ventilation, the work preformed by the ventilator is constant; however, recent data do not indicate a reduction in patient work compared with volume ventilation. ${ }^{16}$

Neurally adjusted ventilatory assist (NAVA) operates similarly to PAV. ${ }^{17}$ The only difference is that NAVA proportionally unloads the patient's inspiratory work of breathing by applying airway pressure per each microvolt increase in the diaphragmatic electromyographic signal. Overall, the application of ventilatory assistance is the same with PAV or NAVA: The greater the patient effort, the greater the ventilator pressure, and the lower the patient effort the lower the ventilator pressure. Thus, the patient, not the ventilator, controls the ventilator pattern. Both PAV and NAVA have been shown to reduce asynchrony compared with PSV. ${ }^{18,19}$

We acknowledge that in very select populations of patients (eg, severe COPD, inappropriately small sized endotracheal tubes, morbid obesity), the approach to performing an SBT may have an impact on time to extubation. However, in a heterogeneous group of patients requiring ventilatory support, we would not expect the approach to an SBT to have an impact on time to extubation. But what we do expect is that the mode of ventilation applied once a patient begins to trigger inspiration has an effect on time to extubation. We would recommend that this trial be repeated with a single approach to the SBT but with different modes of ventilation once controlled ventilation is unnecessary. We expect that the selection of a mode of ventilation (PAV or NAVA) that markedly reduces asynchrony and, as a result, patient work/effort would have a beneficial effect on time to extubation.

Robert M Kacmarek RRT PhD FAARC Department of Respiratory Care Massachusetts General Hospital Department of Anesthesiology Harvard University Boston, Massachusetts

Jesus Villar MD PhD CIBER de Enfermedades Respiratorias Instituto de Salud Carlos III
Madrid, Spain

Multidisciplinary Organ Dysfunction Evaluation Research Network, Research Unit

Hospital Universitario Dr. Negrin Las Palmas de Gran Canaria, Spain

Lluís Blanch MD PhD

CIBER de Enfermedades Respiratorias Instituto de Salud Carlos III Madrid, Spain

Critical Care Center Corporació Sanitaria Universitària Parc Taulí Institut Investigaciói Innovació Parc Taulí Universitat Autònoma de Barcelona Sabadell, Spain

\section{REFERENCES}

1. Carrothers KM, Barr J, Spurlock B, Ridgely MS, Damberg CL, Ely EW. Contextual issues influencing implementation and outcomes associated with an integrated approach to managing pain, agitation, and delirium in adult ICUs. Crit Care Med 2013;41(9 Suppl 1):S128S135.

2. MacIntyre NR, Cook DJ, Ely EW Jr, Epstein SK, Fink JB, Heffner $\mathrm{JE}$, et al. Evidence-based guidelines for weaning and discontinuing ventilatory support: a collective task force facilitated by the American College of Chest Physicians; the American Association for Respiratory Care; and the American College of Critical Care Medicine. Chest 2001;120(6 Suppl):375S-395S.

3. Esteban A, Alía I, Tobin MJ, Gil A, Gordo F, Vallverdú I, et al. Effect of spontaneous breathing trial duration on outcome of attempts to discontinue mechanical ventilation. Spanish Lung Failure Collaborative Group. Am J Respir Crit Care Med 1999;159(2):512518.

4. Brochard L, Rauss A, Benito S, Conti G, Mancebo J, Rekik N, et al. Comparison of three methods of gradual withdrawal from ventilatory support during weaning from mechanical ventilation. Am J Respir Crit Care Med 1994;150(4):896-903.

5. Esteban A, Alía I, Gordo F, Fernández R, Solsona JF, Vallverdú I, et al. Extubation outcome after spontaneous breathing trials with T-tube or pressure support ventilation. The Spanish Lung Failure Collaborative Group. Am J Respir Crit Care Med 1997;156(2):459-465.

6. Teixeira SN, Osaku EF, de Macedo Costa CRL, Toccolini BF, Costa $\mathrm{NL}$, et al. Comparison of proportional assist ventilation plus, T-tube ventilation, and pressure support ventilation as a spontaneous breathing trials for extubation: a randomized study. Respir Care 2015: 60(11):1527-1535. [Epub ahead of print]

7. Bien MY, Shui Lin Y, Shih CH, Yang YL, Lin HW, Bai KJ, et al. Comparisons of predictive performance of breathing pattern variability measured during T-piece, automatic tube compensation, and pressure support ventilation for weaning intensive care unit patients from mechanical ventilation. Crit Care Med 2011;39(10): 2253-2262.

8. Aguirre-Beremo H, Bottiroli M, Italiano S, Roche-Campo F, Santos JA, Alonso M, Mancebo J. [Pressure support ventilation and proportional assist ventilation during weaning from mechanical ventilation]. Med Intensiva 2014;38(6):363-370. Article in Spanish.

9. Costa R, Spinazzola G, Cipriani F, Ferrone G, Festa O, Arcangeli A, et al. A physiologic comparison of proportional assist ventilation with load-adjustable gain factors $(\mathrm{PAV}+)$ versus pressure support ventilation (PSV). Intensive Care Med 2011;37(9):1494-1500. 


\section{SBT to Determine ReAdiness fOR Ventilator Discontinuation}

10. Bosma K, Read B, Nikoo M, Bental T, Harris C, Jones P, et al. A randomized trial comparing weaning from mechanical ventilation on pressure support vs. proportional assist ventilation: a pilot study. Chest 2013;144(4):892A. doi: 10.1378/chest.1704978.

11. Thille AW, Rodriguez P, Cabello B, Lellouche F, Brochard L. Patient-ventilator asynchrony during assisted mechanical ventilation. Intensive Care Med 2006;32(10):1515-1522.

12. de Wit M, Miller KB, Green DA, Ostman HE, Gennings C, Epstein SK. Ineffective triggering predicts increased duration of mechanical ventilation. Crit Care Med 2009;37(10):2740-2745.

13. Sottile PD, Shoeb AH, Piccoli JR, Albers D, Moss M. Development of a computerized algorithm to detect and assess the impact of dyssynchrony on low tidal volume ventilation. Am J Respir Crit Care Med 2015;191(4):A3894.

14. Beitler JR, Malhotra A, Sands SA, Owens RL, Thompson BT, Loring SH, Talmor DS. Occult high tidal volumes from breath stacking dyssynchrony occur commonly during low tidal volume ventilation for ARDS. Am J Respir Crit Care Med 2015;191(4):A3896.
15. Blanch L, Villagra A, Sales B, Montanya J, Lucangelo U, Luján M, et al. Asynchronies during mechanical ventilation are associated with mortality. Intensive Care Med 2015;41(4):633-641.

16. Kallet RH, Campbell AR, Dicker RA, Katz JA, Mackersie RC. Work of breathing during lung-protective ventilation in patients with acute lung injury and acute respiratory distress syndrome: a comparison between volume and pressure-regulated breathing modes. Respir Care 2005;50(12):1623-1631.

17. Kacmarek RM. Proportional assist ventilation and neurally adjusted ventilatory assist. Respir Care 2011;56(2):140-148; discussion 149-152.

18. Xirouchaki N, Kondili E, Vaporidi K, Xirouchakis G, Klimathianaki M, Gavriilidis G, et al. Proportional assist ventilation with loadadjustable gain factors in critically ill patients: comparison with pressure support. Intensive Care Med 2008;34(11):2026-2034.

19. de la Oliva P, Schüffelmann C, Gómez-Zamora A, Villar J, Kacmarek RM. Asynchrony, neural drive, ventilatory variability and COMFORT: NAVA versus pressure support in pediatric patients. A non-randomized crossover trial. Intensive Care Med 2012;38(5):838-846. 